
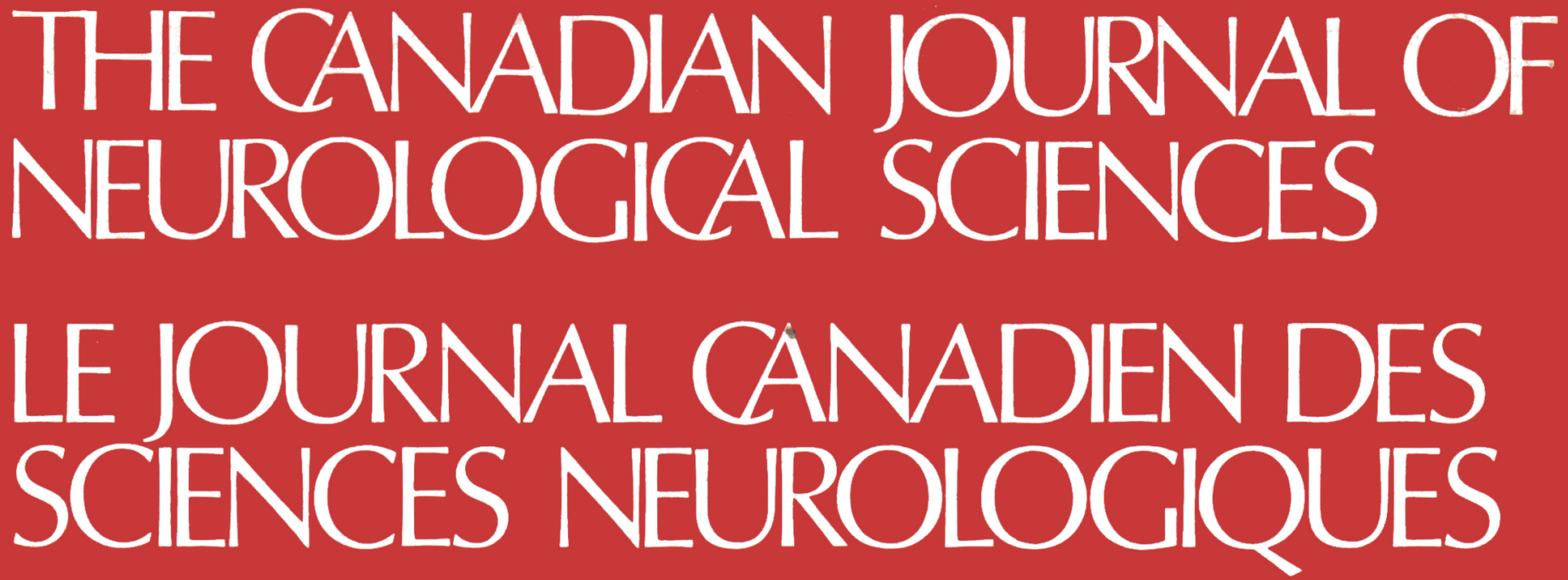

Editorial

Symposium Report

Parallel Processing of Cutaneous Information in the

Somatosensory System of the Cat....

Robert W. Dykes

Stroke in Coronary Bypass Surgery W.R. Wayne Martin and Stanley A. Hashimoto

Plasma Exchange of Malignant Multiple Sclerosis

Heterotopic Growth of Dysplastic Cerebellum in Frontal Encephalocele

in an Infant of a Diabotic Mother

Harvey B. Sarnat, Daphne E. deMello, John D. Blair, and Sateda Y. Siddiqui

Cerebrospinal Fluid and Blood Thiamine Concontrations

in Phenytoin-Treated Epileptics

M.I. Botez, Claude Joyal, Urs Maag and Jocelyne Bachevalier

Lo Méningite de Mollaret

. M. Saint-Martin, F. Duplantis, M. Laverdière, J. Lachapelle, S. Rousseau, L.E. Roy et J. Boileau

Familial Benign Intracranial Hypertension and Depression

................... Edward Coffey, Donald R. Ross, W. Wayne Massey, C. Warren Olanow

Extramedullary Hematopoiesis Simulating

Parasagittal Meningioma

.............................. R.A. Kandel, K.P.H. Pritzker, A.S. Gordon and J.M. Bilbao

New Data on the Genetics of Parkinson's Disease

André Barbeau and Emmanuelle Pourcher

53

Dr. James K. Murray: An Appreciation .................................. Ronald A. Dolan

Notes and Announcements

62

Book Reviows

Official Journal of

The Canadian Neurological Society

The Canadian Neurosurgical Society

The Canadian Society of Clinical Neurophysiologists

The Canadian Association for Child Neurology

XVII Canadian Congress of Neurological Sciences 


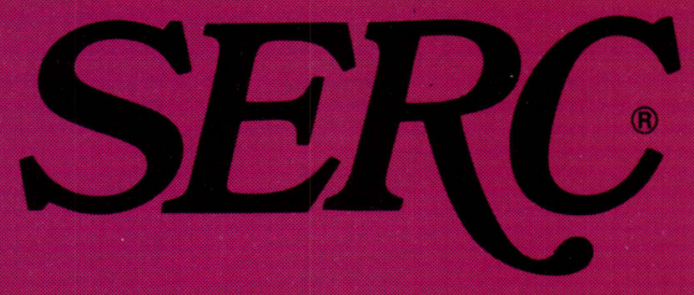

\section{For the management of Vertigo}

- Proven efficacy

"(Serc) is now a proven, useful therapeutic agent in the treatment of Ménière's disease, especially in the control of vertigo."

\section{- Restores vestibular responses}

"In a preliminary trial (Wilmot 1971) using objective testing of both auditory and vestibular function,...the results showed statistical significance in favour of Serc."2

\section{- Reduced severity of episodic vertigo}

\section{"...a significant improvement in favour of the drug (Serc) with regard to vertigo, tinnitus and} deafness. Vertigo was the most responsive symptom."

\section{- Well tolerated}

"No adverse reactions were observed."

\section{REFERENCES:}

PRESCRIBING INFORMATION INDICATIONS: SERC may be of value in reducing the episodes of vertigo in Meniere's disease. No claim is made for the effectivenesS of SERC in the symptomatic treatment of any form of vertigo other than that treatment of any form of vertigo

DOSAGE AND ADMINISTRATION: The usual adult dosage has been one to two tablets ( $4 \mathrm{mg}$. each) administered orally three times a day.

Recommended starting dose is two tablets three times daily. Therapy is then adjusted as needed to maintain patient response. The dosage has ranged from two tablets per day to eight tablets per day. No more than eight tablets are recommended to be taken in any one

day. (betahistine hydrochloride) is not recommended for use in children. As with all drugs, SERC should be kept out of reach of children.

CONTRAINDICATIONS: Several patients with a history of peptic ulcer have experienced an exacerbation of symptoms while using SERC. Although no causua relation has been established SERC is contraindicated in the presence of peptic ulcer and in patients with a history of this condition. SERC is also contraindicated in patients with pheochromocytoma.

PRECAUTIONS: Although clinical intolerance to SERC by patients with bronchial asthma has not been demonstrated, caution should be exercised if the drug is used in these patients.

USE IN PREGNANCY: The safety of SERC in pregnancy has not been established. Therefore, its use in pregnancy or lactation, or in women of childbearing age requires that its potential benefits be weighed against the possible risks.

ADVERSE REACTIONS: Occasional patients have experienced gastric upset, nausea and headache.

HOW SUPPLIED: Scored tablets of $4 \mathrm{mg}$ each in bottles of 100 tablets.

Full prescribing information avaliable on request.

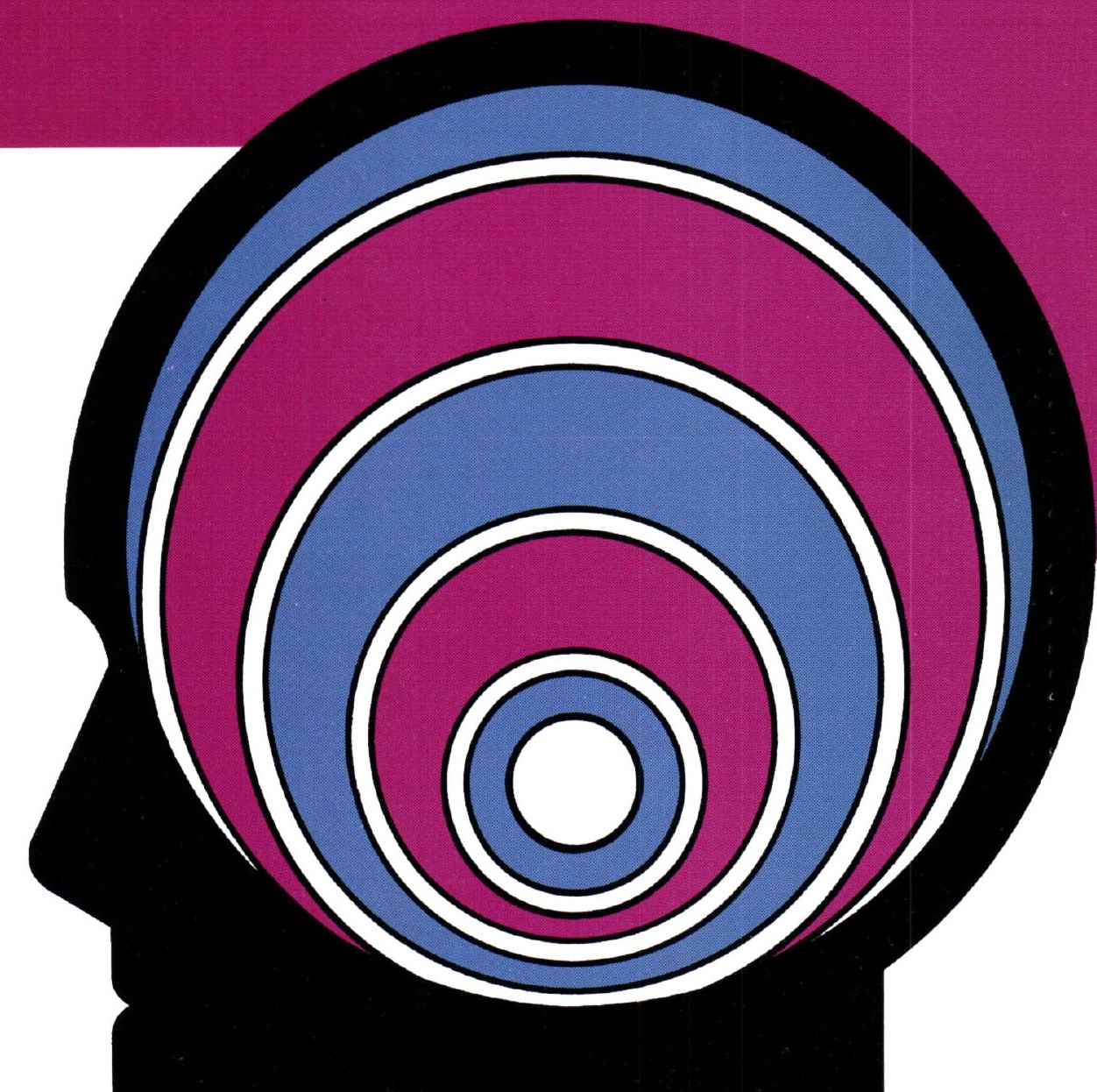




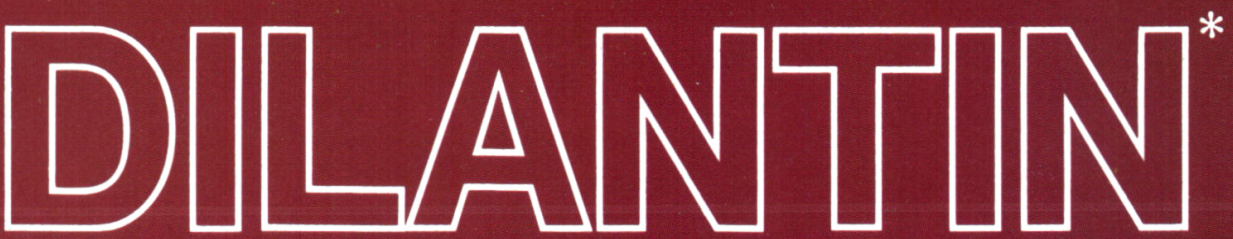

\section{Extended Phenytoin Sodium Capsules U.S.P. A RECOGNIZED DIFFERENCE}

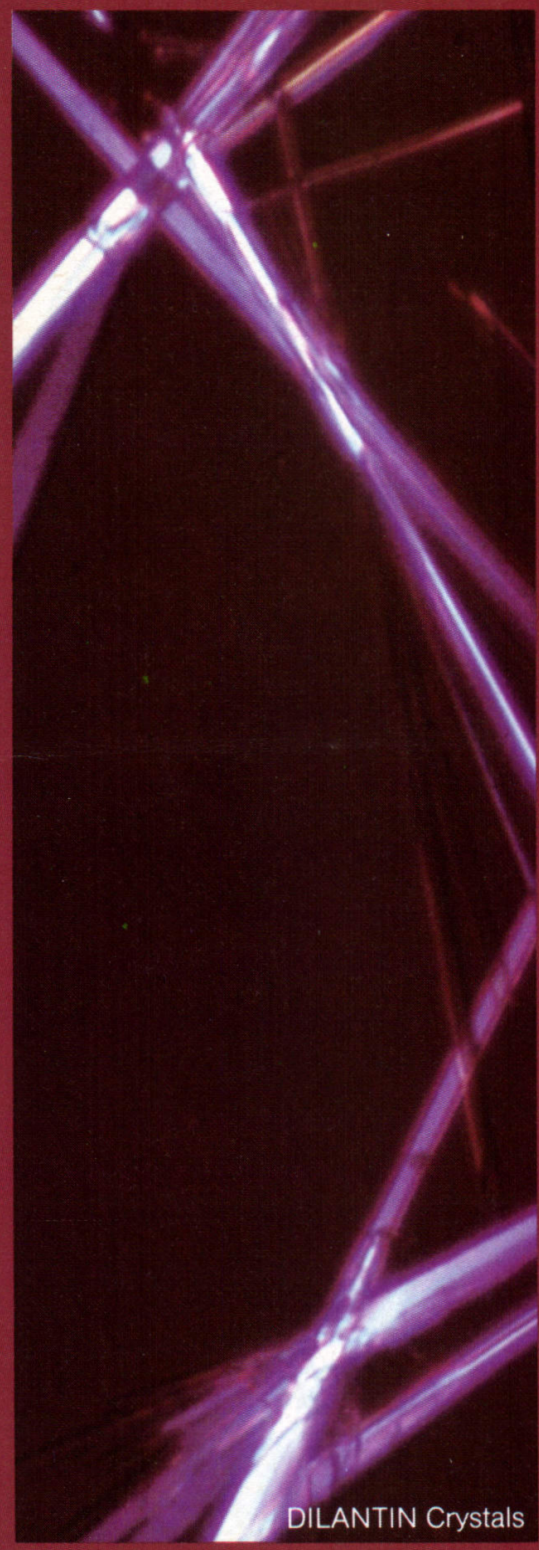

\section{USP XX now differentiates between Extended and Prompt Phenytoin Sodium Capsules.}

Extended phenytoin sodium has been recognized as a distinct pharmaceutical entity. Its slow dissolution and absorption do not create significant fluctuations in phenytoin blood levels.
Prompt phenytoin sodium has a faster dissolution and higher initial blood levels. The two forms of phenytoin sodium are not interchangeable. ${ }^{\star \star}$

\section{DILANTIN Capsules have not changed.}

Extended effect has always been the action of DILANTIN therapy. Only the U.S.P. standards have changed to recognize the difference between "extended" and "prompt" phenytoin sodium Both you and your patient can continue to benefit from the consistent antiepileptic action of DILANTIN capsules.

\section{Once-daily-dosage option is confirmed for DILANTIN Capsules.}

Extended action of DILANTIN offers greater convenience and improved patient compliance. Dependable, effective therapy is now available through a oncedaily-dosage option, once seizure control has been established with divided doses.

\section{DILANTIN formulation ensures dependable bioavailability.}

Extended phenytoin classification of DILANTIN capsules is the result of its unique dissolution profile. Due to its special formulation, DILANTIN exerts a slow, steady release of phenytoin for dependable bioavailability.

**Patients should be maintained on one form of phenytoin (extended or prompt) to avoid toxicity or loss of seizure control.

\section{START WITH DILANTIN-STAY WITH DILANTIN FOR OVER A GENERATION, THE STANDARD IN EPILEPSY MANAGEMENT}




\section{The Roche \\ spectrum of anticonvulsants}

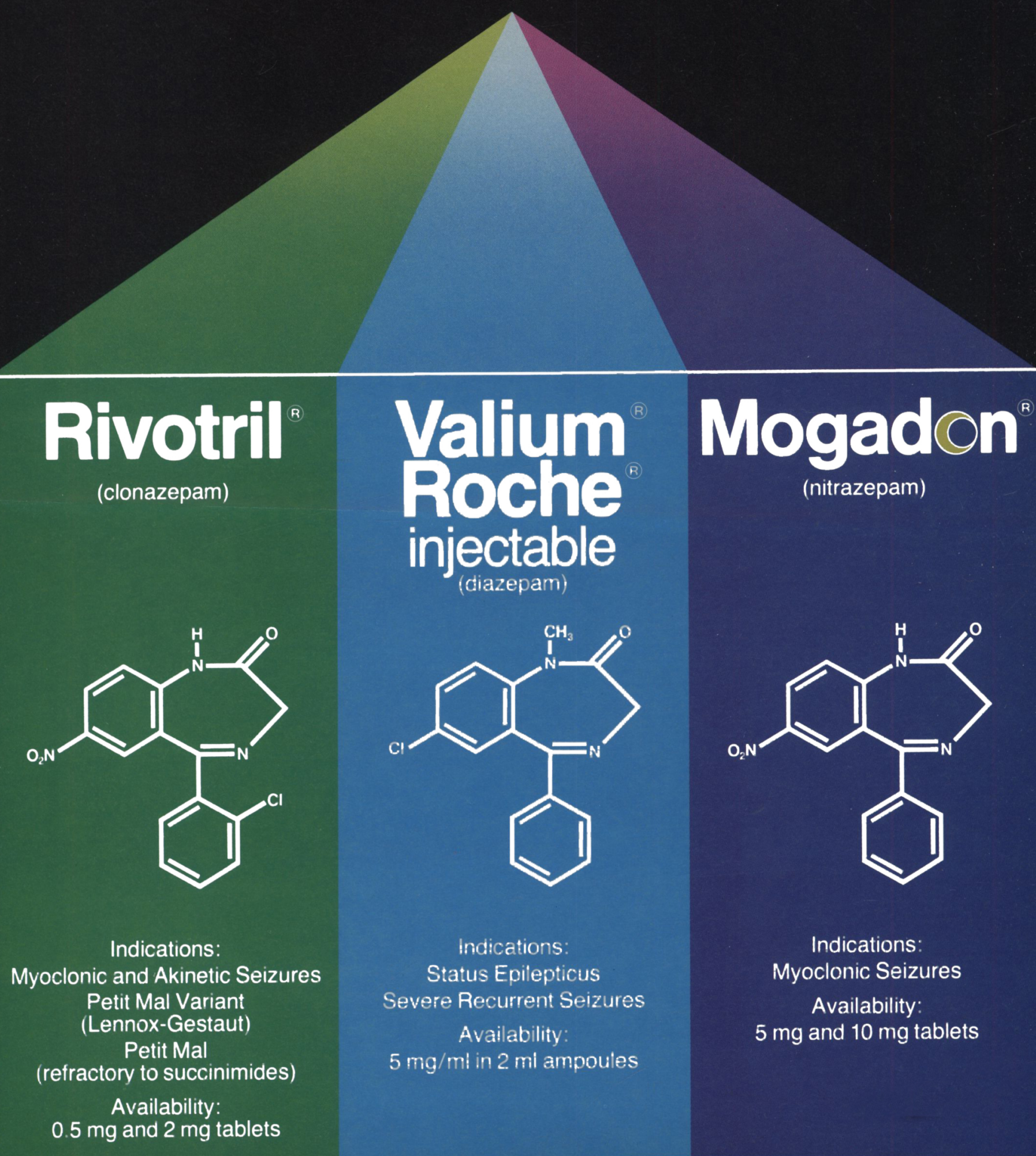




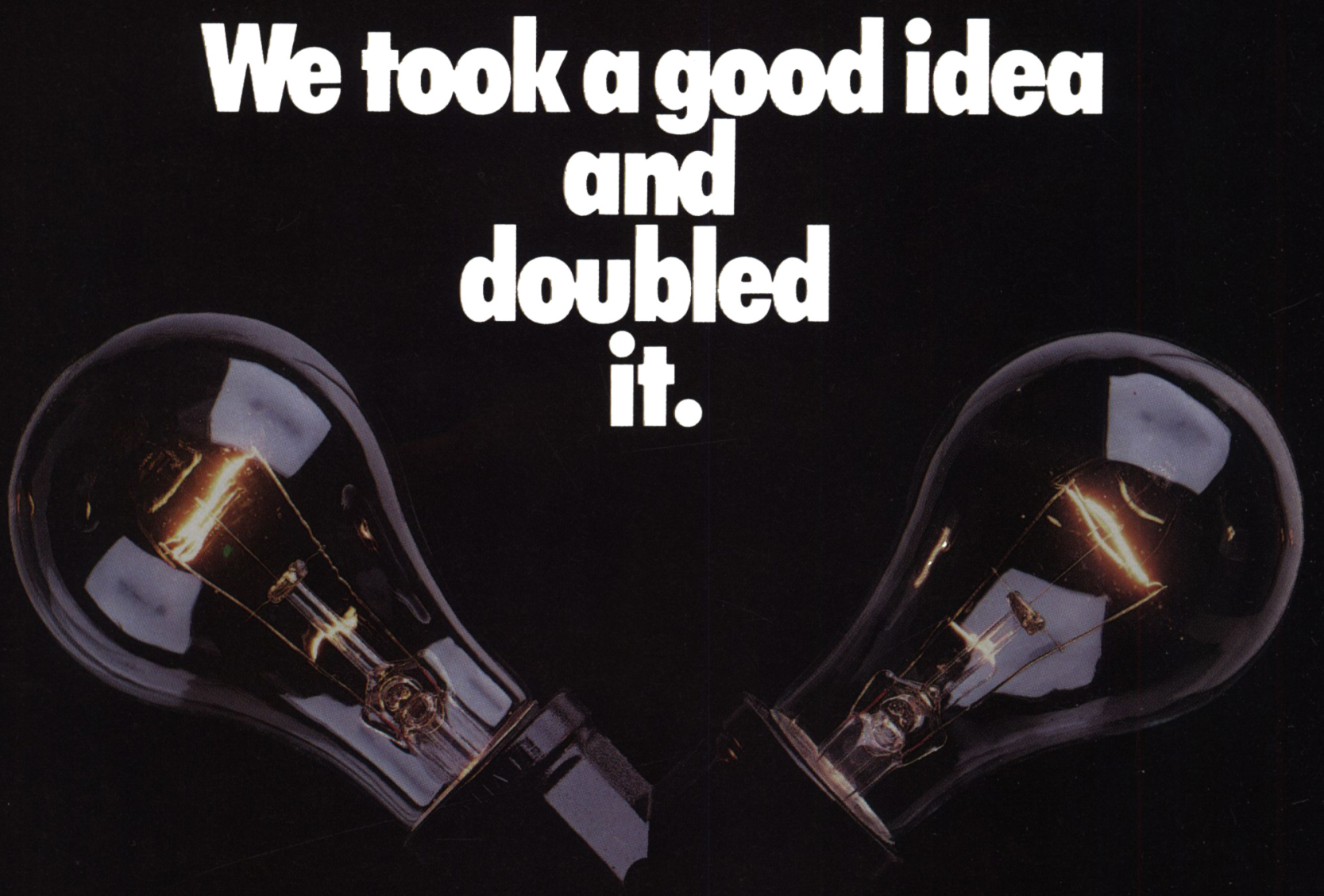

Now you have new strength to fight migraine. New Sandomigran DS is simple, effective headache prophylaxis which encourages good compliance.
For patients who overuse or are refractory to analgesics or ergotamine-choose the strong one, Sandomigran DS.

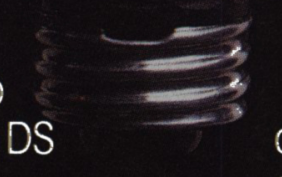




\section{THE CANADIAN JOURNAL OF NEUROLOGICAL SCIENCES LE JOURNAL CANADIEN DES SCIENCES NEUROLOGIQUES}

\section{Editor}

Robert G. Lee

Calgary

\section{Editorial Board}

\section{Albert J. Aguayo \\ Montreal}

Henry J. M. Barnett

London

Paul Bédard

Quebec

Henry B. Dinsdale

Kingston

Guy Geoffroy

Montrea

Alan Hudson

Toronto

Yves Lamarre

Montreal

News Editor

Arthur J. Hudson

London

THE EDITORIAL BOARD wishes to publish original work in the basic and clinical neurosciences on the understanding that it has not been and will not be published elsewhere Review articles on timely subjects will be accepted. Manuscripts must be in triplicate including illustrations. One of the copies must be the original, ribbon copy. Manuscripts should be typed double spaced, on white paper.

Papers will be accepted in French or English. All papers should be accompanied by a short résumé in both languages. The résumé translation will be done by the editorial board if requested.

Papers should be identified only by the full name of the author, or authors, and the name of the place in which the work was done.

ILLUSTRATIONS: Photographs should be unmounted on glossy paper and show magnification scale. They should be marked on the back with figure number, title of paper and name of author.

Diagrams should be in India ink and large enough to be informative after reduction.

All illustrations should be referred to as figures, numbered consecutively, not included in the body of the text and all

\author{
Associate Editor \\ André Barbeau \\ Montreal
}

Bernard Lemieux

William J. Logan

Toronto

Morton Low
Vancouver

Thomas P. Morley

Toronto

Thomas J. Murray

Halifax

Donald Paty

Vancouver

Sidney J. Peerless London

captions should be typed on a separate piece of paper.

Colored illustrations cannot usually be accepted unless the author is prepared to assist with the cost of reproduction.

REFERENCES to authors outside the context of the sentence should read (Name, Year). i.e. "However, a recent study (Bird and Iverson, 1975) showed a decreased, etc." Authors mentioned within the context of the sentence should read Name (Year), "i.e. ...twenty years since Ecker and Reimenshender (1951) demonstrated, etc." References should be typed in alphabetical order on a separate sheet and include author's name, initials, year, title, publication, volume first and last page, i.e. Isacson, $P$. (1967). Myx-oviruses and autoimmunity. Progress in Allergy, 10, 256-292. Abbreviations should be the same as those used in Cumulated Index Medicus.

Textbook references should include name of text, author's name, page number, publisher and city.

REPRINTS: Fifty reprints will be supplied free if ordered when the galley proofs are returned. More may be ordered at a nominal charge. Corrections and changes in the galley proofs, apart from printer's errors may be charged to the author.

This journal is indexed by Index Medicus, Excerpta Medica and Current

\section{Founding Editor}

Robert T. Ross

Winnipeg

Terry Picton

Ottawa

Jean Reiher

Sherbrooke

Leo P. Renaud

Montreal

Barry Rewcastle

Calgary

Matthew W. Spence

Halifax

William G. Tatton

Toronto

Bryce Weir

Edmonton

\section{Editorial Assistant}

Lucile G. Edwards

Calgary

\section{Contents - Clinical Practice and Life} Science.

SUBSCRIPTIONS: This journal is issued four times a year. The annual rate is $\$ 28.00$ for Canada and the U.S.A. $\$ 30.00$ elsewhere. Internes, Residents, Pre-and Post-Doctoral Students, $\$ 14.00$ per annum. Single copies $\$ 10.00$ each.

ADVERTISING: Enquiries regarding advertising space and rates should be directed to LEX LTD. VANCO PUBLICATIONS, 190 Main Street, Unionville, Ontario L3R 2G9. Telephone - (416) 297-2030.

All communications, manuscripts, subscriptions, etc., should be sent to the Editor, Canadian Journal of Neurological Sciences, Faculty of Medicine, 2500 University Drive, Calgary, Alberta, Canada T2N 1N4.

COPYRIGHT @1981 by THE CANADIAN JOURNAL OF NEUROLOGICAL SCIENCES INC. No part of this journal may be reproduced in any form without the prior permission of The Canadian Journal of Neurological Sciences.

Printed by Lawson Graphics Ltd., 708 Moray Street

Winnipeg, Manitoba R3J 3S9.

Mailed under second class registration number 3307. Postage paid at Winnipeg, Manitoba 
The Canadian Journal of Neurological Sciences is the official publication of the participating societies of the Canadian Congress of Neurological Sciences.

$\begin{array}{lll}\text { PUBLICATIONS COMMITTEE } & \\ \text { Donald Baxter } & \text { Andrew Eisen } & \text { Charles Tator } \\ \text { Montreal } & \text { Vancouver } & \text { Toronto }\end{array}$

\section{CANADIAN NEUROLOGICAL SOCIETY}

President

Past President

Vice-President

Secretary-Treasurer
Henry B. Dinsdale

Robert G. Lee

Thomas J. Murray

Robert F. Nelson

Department of Medicine

Ottawa General Hospital

Ottawa, Ontario K 1G 8L6
Council:

Michel Aubé

Michel Drolet

John Humphrey

Andrew Kertesz

Donald McLean

Peter Seland

\section{CANADIAN NEUROSURGICAL SOCIETY}

President

Past President

President Elect

Secretary-Treasurer
Jules Hardy

Peter Allen

Stuart Huestis

Gary Ferguson

University Hospital

London, Ontario N6A 5A5
Council:

Derek Fewer

Alain Godon

Robin Humphreys

Fala Maroun

Terry Myles

André Olivier

\section{CANADIAN SOCIETY OF CLINICAL NEUROPHYSIOLOGISTS \\ President \\ Past President \\ Secretary-Treasurer \\ Andrew Eisen \\ Jean Reiher \\ Warren Blume \\ University Hospital \\ London, Ontario N6A 5A5 \\ Council: \\ Roger Broughton \\ Reda El-Sawy \\ Normand Giard \\ Leroy Heffernan \\ Sherrill Purves}

\section{CANADIAN ASSOCIATION FOR CHILD NEUROLOGY \\ President \\ Past President \\ Vice-President \\ Secretary-Treasurer \\ Rosalind Curtis \\ Warren Blume \\ Fred Andermann \\ Jean Gibson \\ I.W. Killam Hospital \\ P.O. Box 3070 \\ Halifax, Nova Scotia B3J 3G9 \\ Council: \\ Peter Camfield \\ Shashikant Seshia \\ Simon Verrett}


Editorial

Symposium Report

Parallel Processing of Cutaneous Information

in the Somatosensory System of the Cat - Robert W. Dykes

Stroke in Coronary Bypass Surgery

- W.R. Wayne Martin and Stanley A. Hashimoto

Plasma Exchange of Malignant Multiple Sclerosis

- K.G. Warren, P.A. Gordon, T.A. McPherson

Heterotopic Growth of Dysplastic Cerebellum in Frontal

Encephalocele in an Infant of a Diabetic Mother

- Harvey B. Sarnat, Daphne E. deMello, John D. Blair, and Safeda Y. Siddiqui .

Cerebrospinal Fluid and Blood Thiamine Concentrations

in Phenytoin-Treated Epileptics

- M.I. Botez, Claude Joyal, Urs Maag and Jocelyne Bachevalier

Le Méningite de Mollaret - M. Saint-Martin, F. Duplantis,

M. Laverdière, J. Lachapelle, S. Rousseau, L.E. Roy et J. Boileau

Familial Benign Intracranial Hypertension and Depression

- C. Edward Coffey, Donald R. Ross, W. Wayne Massey, C. Warren Olanow ...

Extramedullary Hematopoiesis Simulating Parasagittal Meningioma

- R.A. Kandel, K.P.H. Pritzker, A.S. Gordon and J.M. Bilbao

New Data on the Genetics of Parkinson's Disease

- André Barbeau and Emmanuelle Pourcher

Dr. James K. Murray:

An Appreciation ... Ronald A. Dolan

Notes and Announcements 


\section{Unravel the symptom complex of muscle contraction headache.}

The specific triple action of (C)FIORINAL ${ }^{\circledR}$ Can give the "uptight" headache patient fast relief of the symptom complex of muscle contraction headache. ${ }^{1}$

Fiorinal increases the pain threshold

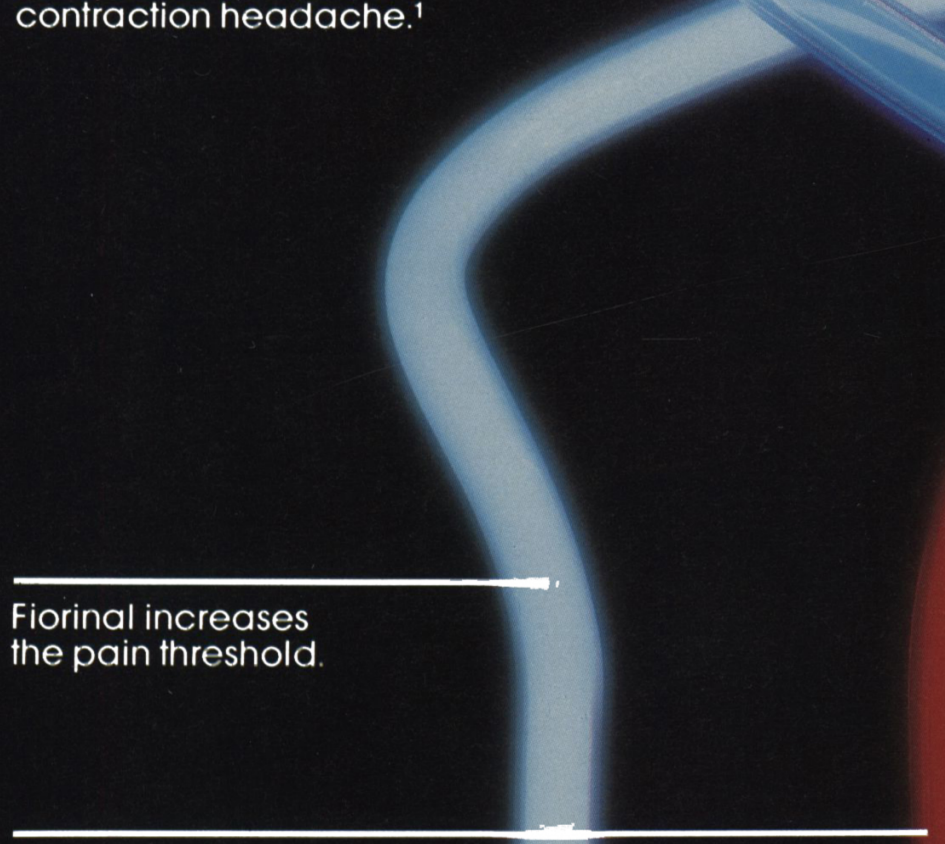

Fiorinal reduces

tension and anxiety.

Fiorinal reduces muscle contraction in scalp, neck and shoulders. 

The precise mechanisms of action of Lioresal (baclofen) are not fully known. It inhibits both monosynaptic and polysynaptic reflexes at the spinal level, probably by hyperpolarization of afferent terminals, although actions at supraspinal sites may also occur and contribute to its clinical effect. Although Lioresal is an analog of the putative inhibitory neurotransmitter gamma-aminobutyric acid (GABA), there is no conclusive evidence that actions on GABA systems are involved in the production of its clinical effects. Peak plasma concentrations of Lioresal are achieved within 2 hours and the plasma half-life is $2-4$ hours. Indications and Clinical Uses

Lioresal (baclofen) is useful for the alleviation of signs and symptoms of spasticity resulting from multiple sclerosis.

Lloresal may also be of some value in patients with spinal cord injuries and other spinal cord diseases.

Contraindications

Hypersensitivity to Lioresal (baclofen)

Abrupt Drug Withdrawal: Following abrupt withdrawal of Lioresal (baclofen) visual and auditory hallucinations, confusion, anxiety with tachycardia and sweating, insomnia, and worsening of spasticity have occurred. Therefore, except for serious adverse reactions, the dose should be reduced slowly when the drug is discontinued. Impaired Renal Function: Because Lioresal is primarily excreted unchanged through the kidneys, it should be given with caution, and it may be necessary to reduce the dosage. Stroke. Lioresal has not significantly benefited patients with stroke. These patients have also shown poor tolerability to the drug. Pregnancy: Safe use of Lioresal during pregnancy or Safe use of Lioresal during pregnancy or
lactation has not been established. High doses lactation has not been established. High doses abdominal hernias in the fetuses of rats and of ossification defects in those of rats and rabbits. Therefore, the drug should be adminis. tered to pregnant patients, or women of child. bearing potential only when, in the judgment of the physician, the potential benefits outweigh the possible hazards.

\section{Precaution}

Safe use of Lioresal (baclofen) in children under age 12 has not been established and it is, therefore, not recommended for use in children. Because of the possibility of sedation, patients should be cautioned regarding the operation of automobiles or dangerous machinery, and activities made hazardous by decreased alertness. Patients should also be cautioned that the central nervous system effects of Lioresal may be additive to those of alcohol and other CNS depressants. Lioresal should be used with caution where spasticity is utilized to sustain upright posture and balance in locomotion, or whenever spasticity is utilized to obtain increased function. Extreme caution should be exercised in patients with epilepsy or a history of convulsive disorders. In such patients, the clinical state and electroencephalogram should be monitored at regular intervals during therapy, as deterioration in seizure control and EEG has been reported occasionally in patients taking Lioresal. Caution should be used in treating patients with peptic

ulceration, severe psychiatric disorders, elderly patients with cerebrovascular disorders, and in patients receiving antihypertensive therapy. It is not known whether Lioresal is excreted in human milk. As a general rule, nursing should not be undertaken while a patient is on a drug since many drugs are excreted in human milk.

\section{Adverse Reactions}

The most common adverse reactions associated with Lioresal (baclofen) are transient drowsiness, dizziness, weakness and fatigue. Others reported: Neuropsychiatric: Headache $(<10 \%)$, insomnia $(<10 \%)$, and, rarely, euphoria, excitement, depression, confusion, hallucinations, paresthesia, muscle pain, tinnitus, slurred speech, coordination disorder, tremor, rigidity, dystonia, ataxia, blurred vision, nystagmus, strabismus, miosis, mydriasis, diplopia, dysarthria, epileptic seizures. Cardiovascular: Hypotension (<10\%), rare instances of dyspnea, palpitation, chest pain, syncope. Gastrointestinal: Nausea, (approx. 10\%), constipation $(<10 \%$ ), and, rarely, dry mouth, anorexia, taste disorder, abdominal pain, vomiting, diarrhea, and positive test for occult blood in stool.

Genitourinary: Urinary frequency $(<10 \%)$, and rarely, enuresis, urinary retention, dysuria, impotence, inability to ejaculate, nocturia, hematuria. Other: Instances of rash, pruritus, ankle edema, excessive perspiration, weight gain, nasal congestion. Some of the CNS and genitourinary symptoms reported may be related to the underlying disease rather than to drug therapy.

The following laboratory tests have been found to be abnormal in a few patients receiving Lioresal: SGOT, alkaline phosphatase and blood sugar (all elevated).

Symploms and Treatment of Overdosage Signs and Symptoms: Vomiting, muscular hypotonia, hypotension, drowsiness, accommodation disorders, coma, respiratory depression, and seizures. The signs and symptoms may be further aggravated by coadministration of a variety of other agents including alcohol, diazepam, and tricyclic antidepressants. Treatment: The treatment is symptomatic. In the alert patient, empty the stomach promptly by induced emesis followed by lavage. In the obtunded patient, secure the airway with a cuffed endotracheal tube before beginning lavage (do not induce emesis). Maintain adequate respiratory exchange; do not use respiratory stimulants. Muscular hypotonia may involve the respiratory muscles and require assisted respiration. A high urinary output should be maintained since Lioresal

(baclofen) is excreted mainly by the kidneys.

Dialysis is indicated in severe poisoning associated with renal failure.

Dosage and Administration

The determination of optimal dosage of Lioresal (baclofen) requires individual titration. Start therapy at a low dosage and increase gradually until optimum effect is achieved (usually between 40-80 mg daily).

The following dosage titration schedule is suggested:

$5 \mathrm{mg}$ t.i.d. for 3 days

$10 \mathrm{mg}$ t.i.d. for 3 days

$15 \mathrm{mg}$ t.i.d. for 3 days

$20 \mathrm{mg}$ t.i.d. for 3 days

Thereafter additional increases may be necessary but the total daily dose should not exceed a maximum of $80 \mathrm{mg}$ daily $(20 \mathrm{mg}$ q.i.d.). The lowest dose compatible with an optimal response is recommended. If benefits are not evident after a reasonable trial period, patients should be slowly withdrawn from the drug (see Warnings).

Availability: Lioresal (baclofen) $10 \mathrm{mg}$ tablets. Description: White to off-white flat-faced, oval tablets with Geigy monogram on one side and the identification code 23 below the monogram. Fully bisected on the reverse side.

Available in bottles of 100 tablets.

\section{References:}

1.R.F. Jones, J.W. Lance, Medical Journal of Australia, 1976, May:654-657.

2.R.G. Feldman: Symposia Reporter, Vol. 3, No. 2 June 1979.

3. Lioresal Product Monograph.

Product monoraph supplied on request.

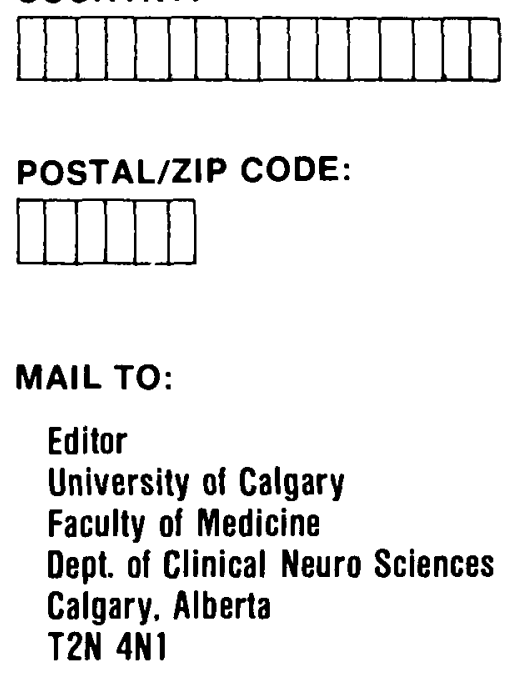

\section{PLEASE NOTIFY US OF YOUR CHANGE OF ADDRESS IN ADVANCE.}

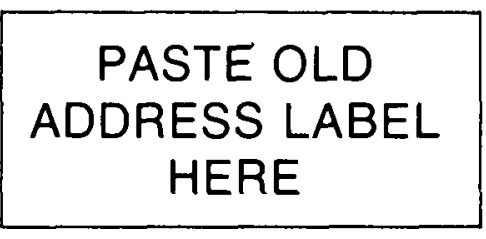

NEW ADDRESS:

NAME:

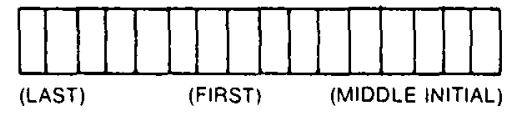

STREET ADDRESS:

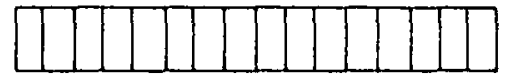

CITY:

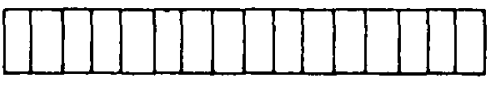

PROVINCE/STATE:

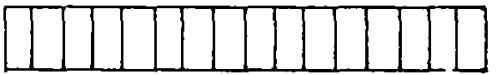

COUNTRY:

$\mathrm{CCPP}$

Geigy Dorval, Qué. H9S 181 


\section{The Advantages of ENTROPHEN*}

\section{To reduce the risk of stroke}

Now, ENTROPHEN* is indicated for reducing the risk of recurrent transient ischemic attacks or stroke in men who have had transient ischemia of the brain due to fibrin platelet emboli. At present there is no evidence that ASA is effective in reducing transient ischemic attacks in women, or is of benefit in the treatment of completed strokes in men or women.

Inhibition of platelet cyclooxygenase activity by a single dose of ENTROPHEN*-10 was comparable to that of plain ASA, although the effect was delayed, reflecting the delayed appearance of ASA in the plasma. ${ }^{1}$

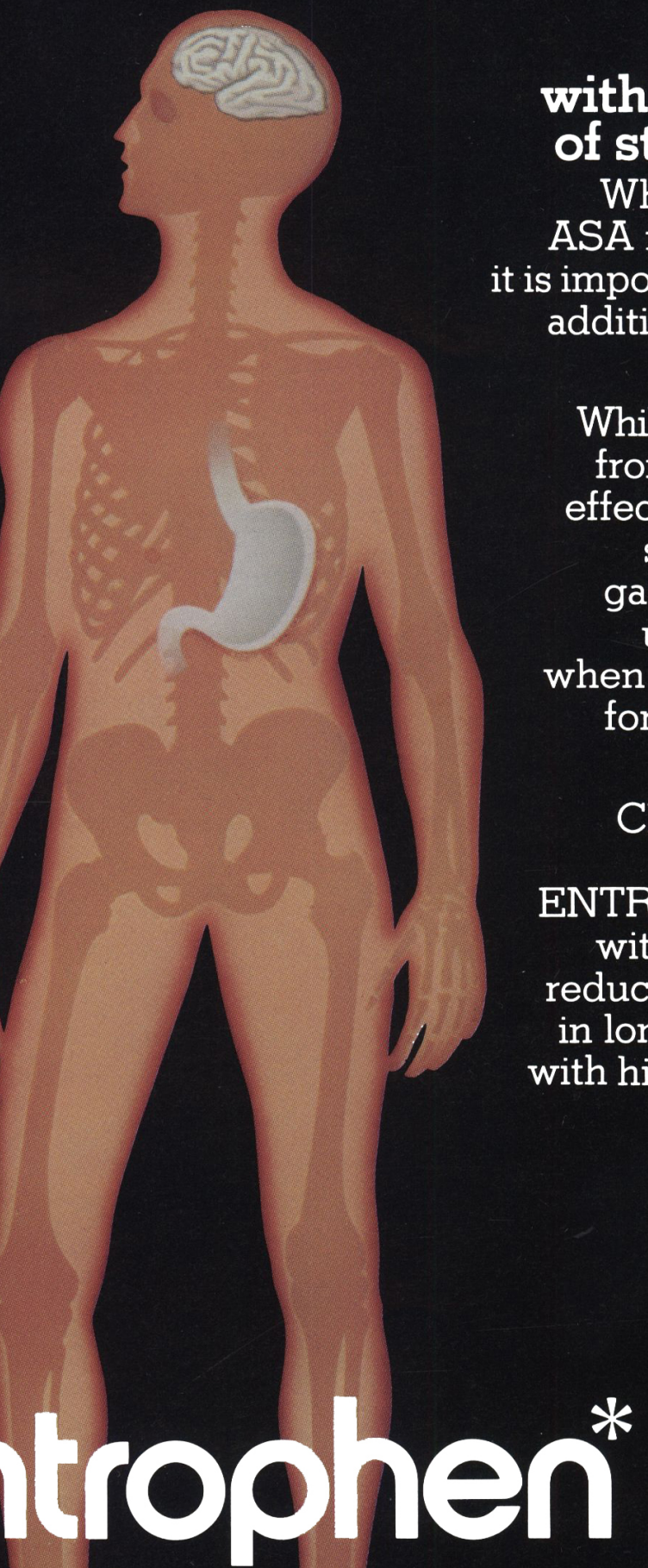

(acetylsalicylic acid tablets, USP) enteric-coated with POLYMER $37^{\star}$
To reduce the risk of stroke with reduced risk of stomach upset 


\section{entroophen*}

(acotylsalicylic acid tablets, USP)

Enteric-costed with POLYMEA 37*

Anti-intlammatory-Analgesic Agent

Platelet Aggregation Inhibitor

\section{DESCRIPTION}

ENTROPHEN* is an enteric-coated tablet containing acetylsalicylic acid coated with POLYMER $37^{*}$, a partially esterified polyvinyl alcohol.

\section{ACTION}

Acetylsalicylic acid (ASA) has analgesic, antipyretic and anti-inflammatory properties.

In rheumatic diseases, although the analgesic and antipyretic effects are useful, the major purpose for which ASA is used is to reduce the intensity of the inflammatory process. Inhibition of prostaglandin synthesis may be involved in the antiinflammatory action of ASA

ASA also alters platelet aggregation and release reaction by inhibiting prostaglandin synthesis Thromboxane $A$ is an essential step in platelet aggregation. ASA prevents Thromboxane $A_{2}$ formation by acetylation of platelet cyclooxygenase mation by acetylation of platelet cyclooxygenase. This inhibition of prostaglandin synthesis is irreversible and attec
life of the platelet.

The POLYMER $37^{\star}$ coating substantially resists disintegration in aqueous fluids having a pH lower than 3.5 for a period of at least 2 hours and is capable of disintegrating in aqueous fluids having a pH of at least 5.5 in from 10 to 30 minutes. Thus. POLYMER $37^{\star}$ coating effectively inhibits the release of ASA in the stomach, whilst allowing the tablet to dissolve in the upper portion of the small intestine for absorption from the duodenal area. Clinical toxperien Clinical experisalce has shown coated acetylsalicylic acid diminishes or eliminates gastric distress during

\section{INDICATIONS}

ENTROPHEN* is indicated whenever gastric intolerance to ASA is of concern.

ENTROPHEN* is indicated for the relief of signs and symptoms of the following:

Osteoarthritis

Rheumatoid arthritis

Spondylitis

Bursitis

and other forms of rheumatism

Musculoskeletal disorders

Rheumatic fever, however, penicillin and other appropriate therapy should be administered concomitantly.

ASA is generally considered to be the primary therapy for most forms of arthritis.

therapy for most forms of arthritis.
ENTROPHEN* is also indicated for reducing the ENTROPHEN* is also indicated for reducing the
risk of recurrent transient ischemic attacks or stroke in men who have had transient ischemia of the brain due to fibrin platelet emboli. At present there is no evidence that ASA is effective in reducing transient ischemic attacks in women, or is of benefit in the treatment of completed strokes in men or women.

\section{CONTRAINDICATIONS}

\section{Sensitivity to the ingredients}

Active peptic ulcer

Patients who had a bronchospastic reaction to ASA or non-steroidal anti-inflammatory drug

\section{WARNINGS}

ASA is one of the most frequent causes of occidental polsoning in toddlers and infants. of the reach of all children.

\section{PRECAUTIONS}

Salicylates should be administered with caution to patients with asthma and other allergic conditions, with a history of gastrointestinal ulcerations with bleeding tendencies, with significant anemia or with hypoprothrombinemia.

Salicylates can produce changes in thyroid function tests.

Acute hepatitis has been reported rarely in patients with systemic lupus erythematosus and patients with systemic lupus enthematosus and juvenile rheumatoid arthritis with plasma sali-
cylate concentrations above $25 \mathrm{mg} / 100 \mathrm{~mL}$.
Patients have recovered upon cessation of therapy.

Use in Pregnancy

ASA does not appear to have any teratogenic effects. ASA has been found to delay parturition in rats. This effect has also been described with non-steroidal anti-inflammatory agents which inhibit prostaglandin synthesis.

High doses ( $3 \mathrm{~g}$ daily) of ASA during pregnancy may lengthen the gestation and parturition time. Because of possible adverse effects on the neonate and the potential for increased maternal blood loss. ASA should be avoided during the las three months of pregnancy.

Drug Interactions

Caution is necessary when ENTROPHEN* and anticoagulants are prescribed concurrently, as aSA may potentiate the action of anticoagulants. Salicylates may potentiate sulfonylurea hypoglycemic agents. Large doses of salicylates may have a hypoglycemic action, and thus, affect the insulin requirements of diabetics.

Although salicylates in large doses are uricosuric agents, smaller amounts may depress uric acid clearance and thus decrease the uricosuric effects of probenecid sulfinpyrazone and phenylbutazone.

Sodium excretion produced by spironolactone may be decreased in the presence of salicylates Saticylates also retard the renal elimination of methotrexate.

\section{ADVERSE REACTIONS}

Gastrointestinal reactions: nausea, vomiting. diarrhea, gastrointestinal bleeding and/or ulceration. Ear reactions: tinnitus, vertigo, hearing loss. Hematologic reactions: leukopenia, thrombocytopenia, purpura. Dermatologic and Hypersensitivity reactions: urticaria, angioedema, pruritus. various skin eruptions. asthma and anaphylaxis. Miscellaneous reactions: acute reversible hepato toxicity, mental confusion, drowsiness. sweating and thirst.

\section{SYMPTOMS AND TREATMENT \\ OF OVERDOSAGE}

Symptoms

In mild overdosage these may include rapid and deep breathing. nausea, vomiting (leading to
alkalosis). hyperpnea, vertigo. tinnitus, flushing. alkalosis), hyperpnea, vertigo. tinnitus, flushing. sweating. thirst and tachycardia. (High blood
levels of ASA lead to acidosis.) Severe cases may show fever, hemorrhage, excitement. confusion. convulsions or coma, and respiratory failure.

Treatment

Treatment is essentially symptomatic and sup portive. Administer water, universal antidote and remove by gastric lavage or emesis. Force fluids (e. salty broth) to replace sodium loss. If the patient is unable to retain fluids orally, the alkalosis patient is unable to retain fluids orally, the alkalosis can be treated by hypertonic saline intravenously. If salicylism acidosis is present, sodium bicarbonate intravenously is preferred because it increases the renal excretion of salicylates
Vitamin $K$ is indicated if there is evidence of hemornage. Hemodialysis has been used with success.

Respiratory depression may require artificial ventilation with oxygen. Convulsions may best be treated by the administration of succinycholine treated and ificial ventilation with nervous system depressant agents should not be used.

Hyperthermia and dehydration are immediate threats to life and initial therapy must be directed to their correction and to the maintenance adequate renal function. External cooling with cool water or alcohol should be provided quickly to any child who has a rectal temperature ove $104^{\circ} \mathrm{F}$

\section{Dosage and aDministration}

\section{Analgesic; antipyretic}

Up to $2.925 \mathrm{~g}$ daily as necessary

Anti-inflammatory

Because the suppression of inflammation in creases with the dose of salicylate even beyond the point of toxicity, the therapeutic objective is to employ as large a dose as possible shor of toxicity. Most patients will tolerate blood salicylat levels in the range of 20 to $25 \mathrm{mg}$ per cent. The most common reason for failing to obtain a therapeutic response to ASA is the administration of inadequate doses.
The generally accepted way to achieve offective 'anti-inflemmatory' salicylato blood levels of 20 to $25 \mathrm{mg}$ per cent is to titrate the dosage by starting with 2.6 to $3.9 \mathrm{~g}$ daily, according to the size, age with 2.6 to $3.9 \mathrm{~g}$ daily, according to the size, age and sex of the patient. If necessary, the dosage is 0.65 o until symptoms of salicylism 8.9. . auditor symptoms, occur. Then, the dosage is decreased by $0.65 \mathrm{~g}$ daily until these symptoms disappea end maintained at that level as long as necessary. In adults the median dose at which tinnitus develops is $4.5 \mathrm{~g}$ per day, but the range extends from 2.6 to 6.09 per day.

Intermittent administration is ineffective. Patients should be advised not to vary the dose from day to day depending on the level of pain because that often fluctuates independently of the intensity of the inflammation. A continuous regimen of $0.65 \mathrm{~g}$ four times daily is considered to be minimum therapy for adults. ENTROPHEN should be administered four times daily. For nighttime and early morning benefits, the last dose should be given at bedtime.

Once maintenance dose is established, ENTROPHEN*-15 may be useful to encourage patient compliance.

Optimally, salicylate therapy should be monitored by periodic blood salicylate level determinations. If this is not practical, the appearance of auditory symptoms in the form of tinnitus or deatness are acceptable as an indication of the maximum tolerated salicylate dose.

There is an inverse relation between blood salicylate levels at which auditory symptoms appear and the age of the patient. In the young aduit, this is usualiy in the range of 20 to $30 \mathrm{mg}$ per cent. In children, however, the level may be much higher, or the effect apparently absent. Because salicylate toxicity may appear withou Because salicylate toxicity may appear withou such warning in children. the usual practice is to give ASA in a caily dose of 50 to $100 \mathrm{mg}$ per aiming for a concentration of about $30 \mathrm{mg}$ per cent. Ahoumatic Fover

A total daily dosage of $100 \mathrm{mg}$ per kilogram of body weight administered in divided doses to allay the pain, swelling and fever.

Cerebral ischemic attacks (men)

The recommended dosage is $1,300 \mathrm{mg}$ per day (650 $\mathrm{mg}$ twice a day or $325 \mathrm{mg}$ four times a day). AVAILABILITY

No. 472-ENTROPHEN*-15 tablets containing $975 \mathrm{mg}$ of acetylsalicylic acid USP. coated with POLYMER $37^{*}$. Oval, pale yellow, film-coated tablets with the FROSST name engraved on one face and 472 on the other and supplied in bottles of 100 and 500 .

No. 470-ENTROPHEN*-10 tablets containing $650 \mathrm{mg}$ of acetylsaticylic acid USP, coated with POLYMER $37^{*}$. Oval, orange, film-coated tablets. with the FROSST name engraved on one face and $\mathbf{4 7 0}$ on the other and supplied in bottles of 100,500 and 1,000 .

No. 438-ENTROPHEN*-5 tablets containing $325 \mathrm{mg}$ of acetylsalicylic acid USP. coated with POLYMER $37^{\circ}$. Round, brown, film-coated tablets. with the FROSST name engraved on one face and 438 on the other and supplied in bottles of 100,500 and 1,000

FULL PRODUCT MONOGRAPH AVAILABLE ON REOUEST.

$1-188$
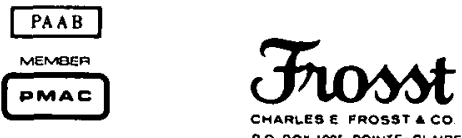

" Trademark 

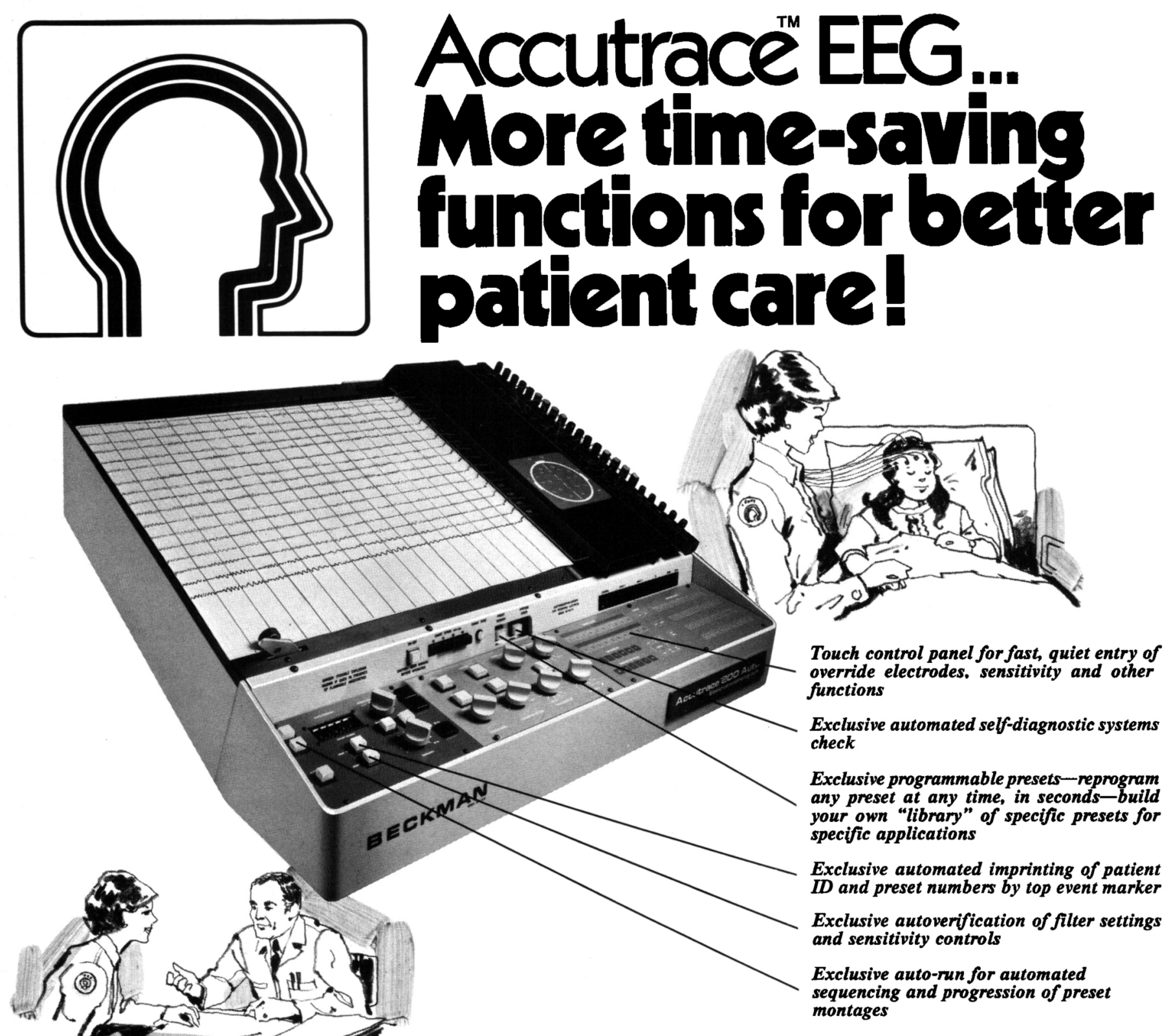

When your EEG automatically prints the patient's ID and preset numbers as part of the permanent record, verifies six major control settings, then proceeds to produce a 20-page record in each of the first six preset montages. . . two things are obvious.

First, the Technician has more time than ever before to devote to caring for the patient. This is exceptionally important when dealing with difficult or confused subjects.

Second, the instrument being used is an Accutrace model 200A.

Presets can be adjusted immediately at the touch of a button to correspond to the patient's current condition. A remote marker lets you flag important events on the record... even while you are at the patient's bedside.

When you add ease of mobility, the safety assurances of Patient Isolation and immediate help with any problem through the Accutrace Hotline, it is easy to see why more and more health care professionals are turning to Beckman.

To receive further information on the Accutrace 200A, our acclaimed EEG Workshops, or the financial alternatives to a cash purchase, just call (312) 671-3300 collect, or mail this coupon today.
Beckman Instruments, Inc.
Health Care Products
3900 River Road
Schiller Park, Illinois 60176
Please send me information on:
$\square$ The Accutrace model 200A EEG
Beckman EEG Workshops
Financial alternatives to a cash
purchase
Name__Please print)
Inst./Dept___ Title__ State__ Zip__
Address___
Telephone 


\section{Mobile, stable and optically}

unicue: Surgical operating

\section{microsco}

The brand-new concepts of the WILD Surgical Operating Microscopes offer decisive advantages for microsurgery.

- See more with the refined optical system

- Position comfortably with the articulated, balanced modular design

- Work confidently with the rugged, stable stand and the sterilisable controls - Expand individually for photography, cine and TV without special modifications

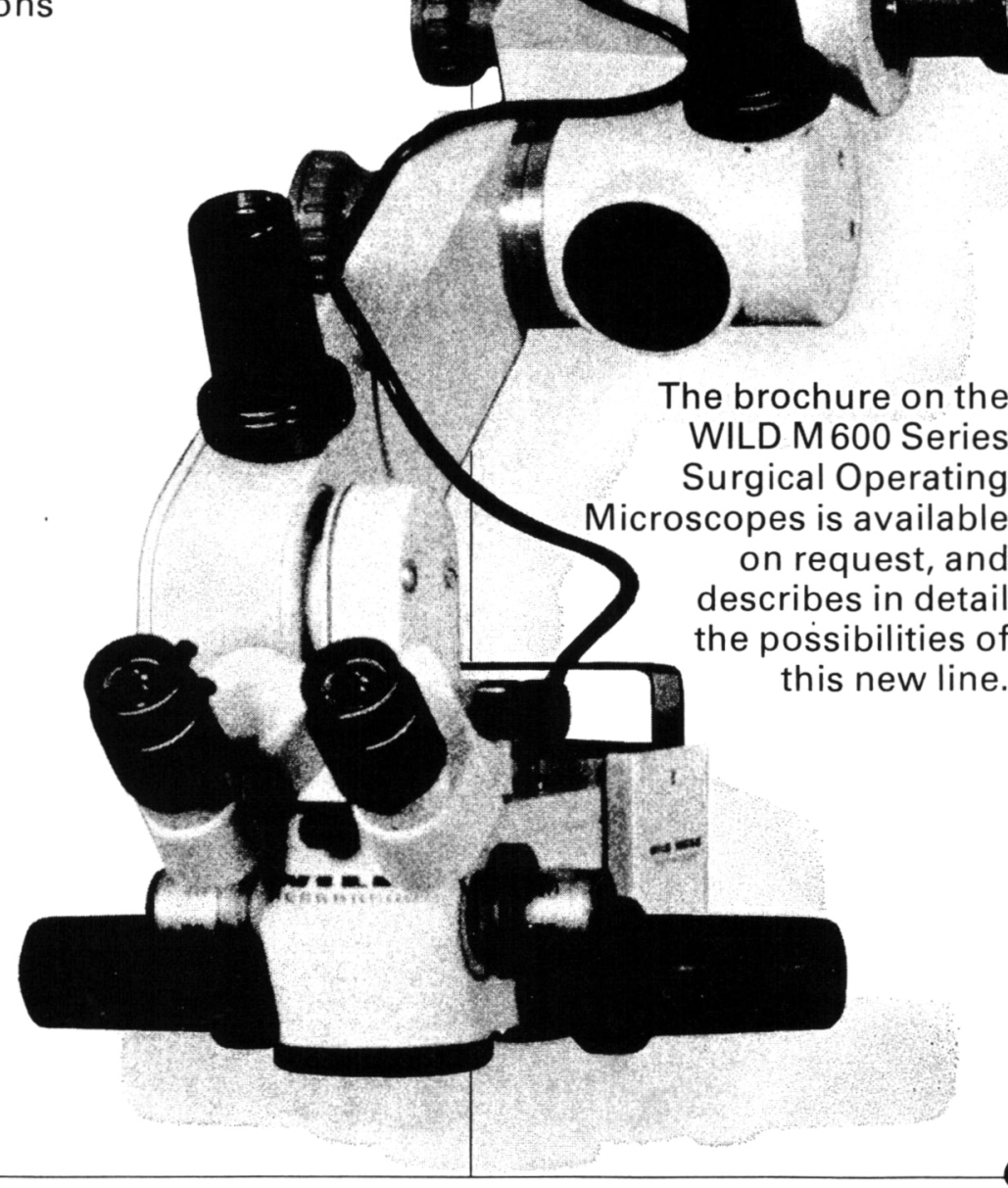
pes of the Wild M600
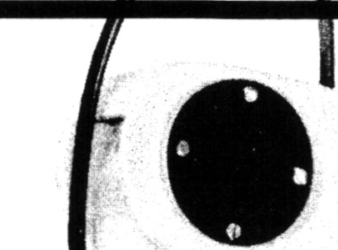
Operating Microscope on MS-C floor stand, rollable

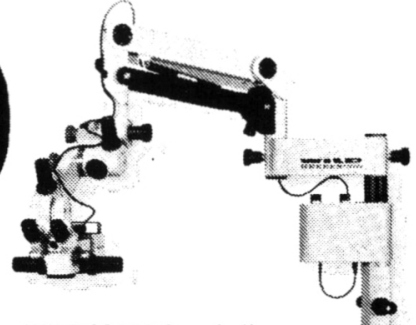




\section{New Vira-A Parenteral}

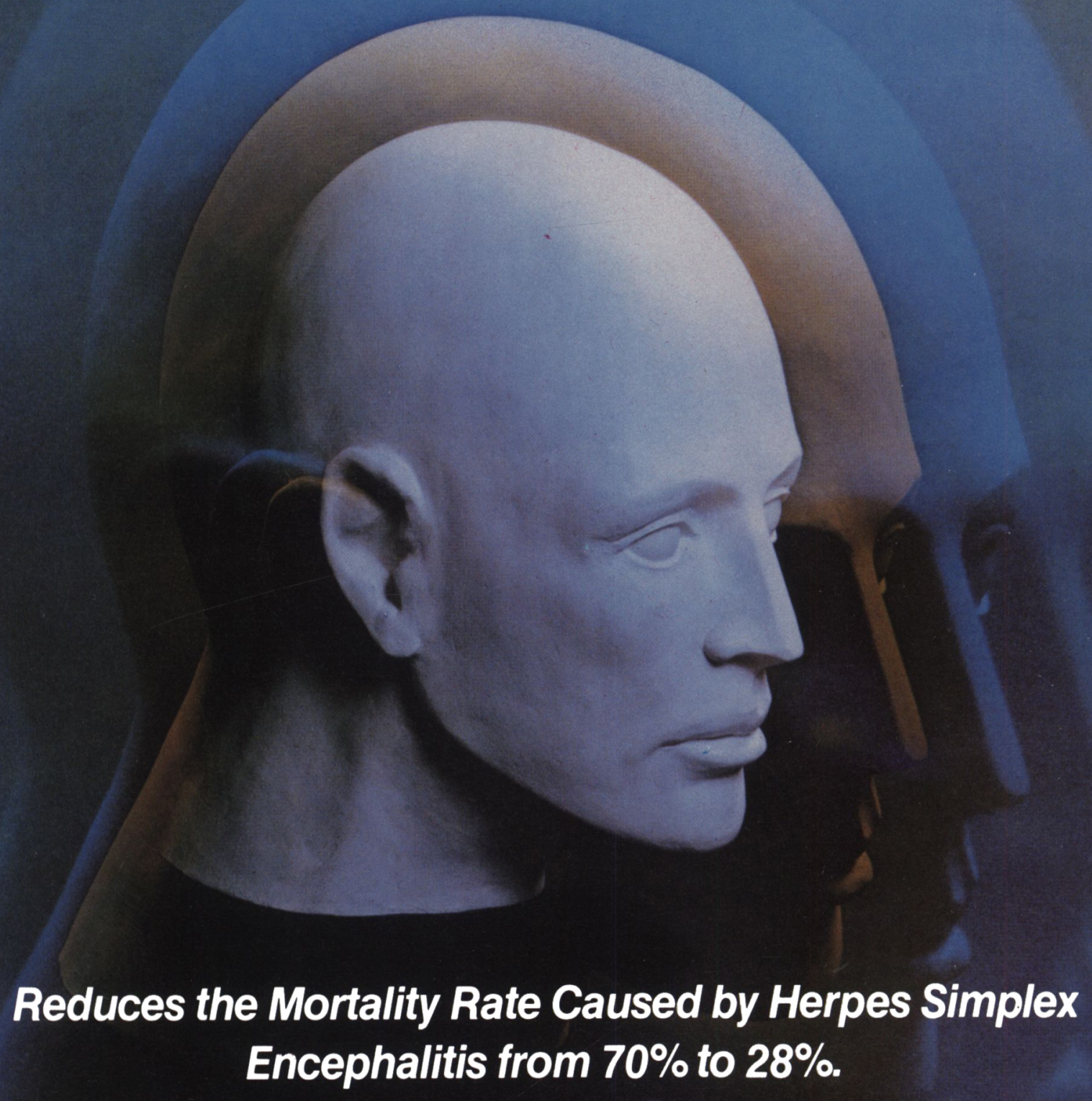

Vira-A Parenteral, a major new development from Parke-Davis Research, significantly reduces the mortality rate of patients with herpes simplex encephalitis.

In controlled studies, Vira-A Parenteral (vidarabine for infusion) reduced the mortality rate caused by herpes simplex encephalitis from $70 \%$ to $28 \%$. Over $50 \%$ of treated survivors had no or only moderately debilitating neurologic sequelae. (1)
Additional evidence suggests that Vira-A Parenteral prevents the reproduction of herpes simplex without substantial interference with the normal function of the patient's own cells. (2)

All hospital pharmacies have been provided with full prescribing information. If further information is required, contact the Medical Director, Parke, Davis and Company, Ltd

\section{PARKE-DAVIS}


Vira-A

(Sterile Vidarabine for Infusion)

\section{THERAPEUTIC OR
PHARMACOLOGICAL CLASSIFICATION Antiviral Agent}

\section{STRUCTURAL FORMULA
AND CHEMISTRY}

Molecular Formula: $\mathrm{C}_{10} \mathrm{H}_{1} \mathrm{~N}_{5} \mathrm{O}_{4} . \mathrm{H}_{2} \mathrm{O}$ Molecular Weight: 285.2

Chemical Name: $9-\beta-D$-arabinoturanosyladenine monohydrate.

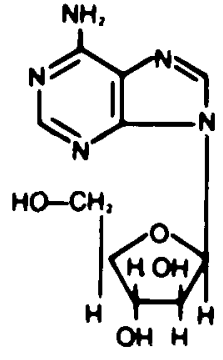

$\cdot \mathrm{H}_{2} \mathrm{O}$
Description: Vira-A (Vidarabine) is a white, crystalline solid. The solubility is $0.45 \mathrm{mg} / \mathrm{ml}$ at Action. Vira-A, an antivisal drug, is a purine nucleoside obtained from fermentation Action. Vira-A, an antivisal drug, is a purine nucleoside obtained from termentation
cultures of Stroptomyces antibioficus. Vira-A possesses in vitro and in vivo antiviral activity cultures of Sireptomyces antibiolicus.
against Herpesvirus Simplex (Herpes Simplex virus) types 1 and 2 .

The antiviral mechanism of action has not yet been established. The drug is converted into nucleotides which appear to be involved with the inhibition of viral replication. In KB into nucleotides which appear to be involved with the inhibition of viral replication. In
cells infected with Herpes Simplex virus type 1. Vira-A inhibits viral DNA synthesis. Excretion of Vira-A is principally via the kidneys. Vira-A is rapidly deaminated to Ara- $\mathrm{Hx}$ (arabinosylhypoxanthine), the principal metabolite. Ara-Hx also possesses in vitro anti-
viral activity but this activity is significantly less than Vira-A Forty-one to $53 \%$ of the viral activity but this activity is significantly less than Vira-A Forty-one to $53 \%$ of the daily dose is cumulatively recovered in the urine as Ara. $\mathrm{Hx}$ with 1 to $3 \%$ appearing as the parent compound. Steady slate urinary excretion of Vira-A and Ara-Hx is attained by day 3 tollowing the first infusion. The urinary excretion rate of Vira-A is generally constant over
the 12 hours during infusion and the 12 hours post-infusion. There is no evidence of fecal the 12 hours during infusion and the
excretion of drug or metabolite.

Indications and Clinical Use. Vira-A is indicated in the treatment of Herpes Simplex virus encephalitis. Controlled studies indicate that Vira-A therapy reduced the mortality rate due to Herpes Simplex virus encephatitis from 70 to $28 \%$.

Vira-A treatment has no beneficial effect on the neurological sequelae present at the time of initiation of therapy. Therefore. early diagnosis and treatment are essential

Herpes Simplex virus encephalitis should be suspected in patients with a history of an
acute febrile encephalopathy associated with disordered mentation, altered level of acute febrile encephalopathy associated
consciousness and focal cerebral signs.

Studies which may support the suspected diagnosis include examination of cerebrospinal fluid and localization of an "intra-cerebral lesion" by brain scan, electroencephalography or computerized axial tomography (CAT).

Brain biopsy is required in order to confirm the etiological diagnosis by means of virat isolation in cell cultures

Detection of Herpes Simplex virus in the biopsied brain tissue can aiso be reliably done by specific fluorescent antibody techniques. Detection of Herpes virus-like particles by electron microscopy or detection of intranuclear inclusions by histopathologic echniques only provides a presumplive diagnosis.

There are no reports avaliable o indicate that Vira-A for infusion is effective in the management or encephalitis due to varicella-zoster or vaccinia viruses. Vira-A is not effective against infections caused by adenovirus or RNA viruses. It is also not effective against cytomegalovirus. vaccinia virus, or smallpox virus.

Contraindications. Vira-A is contraindicated in patients who develop hypersensitivity reactions to it.

Warnings. Vira-A should not be administered by the intramuscular or subcutaneous route because of its low solubility and poor absorption.

Procautions. Treatment should be discontinued in the patients with a brain biopsy negative for Herpes simplex virus in cell culture, unless an obvious diagnosis of Herpes evaluation.

Special care should be exercised when administering Vira-A to patients susceptible to fluid overloading or cerebral edema. Examples are patients with CNS infections and impaired renal function.

Patients with impaired renal function, such as post-operative renal transplant recipients, may have a slower rate of renal excretion of Ara-Hx. Therefore, the dose of Vira-A may need to be adjusted according to the severity of impairment. These patients should be very carefully monitored.

Patients with impaired liver function should also be monitored for possible adverse effects.

Appropriate hematologic tests are recommended during Vira-A administration since hemoglobin, hematocrit, white blood cells, and platelets may be depressed during

In addition to hematologic values, close monitoring of liver function, renal function, and neurological status is strongly encouraged while using Vira-A.

A case of post-infectious encephalomyelitis resulting in a lasting mental impairment of the patient has been reported after an initially successful treatment of Herpes Simplex encephalitis with Vira-A. A second course of treatment with the same drug did not alleviate the symptoms. It is important to monitor this complication in patients who survive the acute encephalitic phase of herpes simplex virus infection.

Some degree of immunocompetence must be present in order for Vira-A to achieve clinical response.

Usago In Prognancy. Vira-A given parenterally is teratogenic in rats and rabbits. Doses of $5 \mathrm{mg} / \mathrm{kg}$ or higher given intramuscularly to pregnant rabbits during organogenesis in pregnant rabbits. Vira-A doses ranging trom 30 to $200 \mathrm{mg} / \mathrm{kg}$ were given intramuscularly to pregnant rats during organogenesis; signs of maternal toxicity were induced at doses of $100 \mathrm{mg} / \mathrm{kg}$ or higher and trank fetal anomalies, with an incidence of $>90 \%$, were found at dose levels of $150 \mathrm{mg} / \mathrm{kg}$ and higher. Lower doses $(30-100 \mathrm{mg} / \mathrm{kg})$ had inconsistent, though positive, effects.

A safe dose for the human embryo or fefus has not been established. Consequently, the use of Vira-A in pregnant patients should be limited to life-threatening illnesses where the possible benefits outweigh the potential risks involved

It is not known whether Vira-A is excreted in human milk. As a general rule nursing should not be undertaken while a patient is under treatment since many drugs are excreted in human milk. However, Vira-A is rapidly deaminated in the gastro-intestina tract.
Adverse Reactions. The principal adverse reactions involve the gastro-intestinal tract and are anorexia, nausea, vomiting, and diarrhea. These reactions are usually mild to moderate, and seldom require termination of Vira-A therapy. Occasional cases with severe discomfort requiring cessation of therapy have been reported.

Neurological complications have been reported at therapeutic doses. These are tremor, dizziness, hallucinations, disorientation, major motor seizures. confusion, psychosis, and ataxia.

Hematologic clinical laboratory changes noted in controlled studies were a decrease in hemoglobin or hematocrit, total white blood cells, granulocytes and platelets. SGOT

elevations were also observed. Other changes o
reticulocyte count and elevated total bilirubin. Other symptoms which have been reported are sharp pain of parotid or masseter muscles, weight loss, malaise, pruritus, rash, hematemesis, and pain at the injection site. Symptoms, and Treatment Ot Overdosage. Acute massive overdose of the intravenous form has been reported without any serious evidence of adverse effect. Acute water overloading would pose a greater threat to the patient than Vira-A, due to its low solubility. Doses of Vira-A over $20 \mathrm{mg} / \mathrm{kg} /$ day can produce bone marrow depression with concomitant thrombocytopenia and leukopenia. If a massive overdose of the intravenous
form occurs, hematologic, neurologic, tiver, and renal functions should be carefully monitored. Treatment should be chiefly symptomatic.

Acute massive oral ingestion is not expected to be toxic because drug absorption from the gastrointestinal tract is minimal. The oral LD so for Vira-A is greater than $5.020 \mathrm{mg} / \mathrm{kg}$ in mice and rats

Dosage and Administration. CAUTION-THE CONTENTS OF THE VIAL MUST BE RAPID OR BOLUS INJECTION MUST BE AVOIDED.

Dosage. Herpes Simplex virus encephalitis $15 \mathrm{mg} / \mathrm{kg} /$ day for 10 days

Method of Preparation. Each vial contains $200 \mathrm{mg}$ of Vira-A per $\mathrm{ml}$ of suspension. The solubility of Vira-A in intravenous infusion fluids is limited. Each one $\mathrm{mg}$ of Vira-A requires $2.22 \mathrm{ml}$ of intravenous infusion fluid for complete solubilization. Therefore, each one litre of intravenous infusion fluid will solubilize a maximum of $450 \mathrm{mg}$ of Vira- $A$.

The following intravenous infusion fluids are compatible with Vira.A and may be used as diluents:

$5 \%$ Dextrose injection USP

$5 \%$ Dextrose plus $0.9 \%, 0.33 \%$ or $0.45 \%$ sodium chloride injection USP or Lactated Ringer's injection USP.

Biologic or colloidal fluids (e g. blood products, protein solutions, etc.) are not suitable as diluents.

Shake the Vira-A well to obtain a homogeneous suspension before measuring and transferring

Prepare the Vira-A solution for intravenous administration by aseptically transterring infusion fluido of Vira-A into an appropriate intravenous infusion fluid. The intravenous $100^{\circ} \mathrm{H}$ to facilitate to prepare the Vira-A solution may be prewarmed to $36^{\circ}$ \% $40^{\circ} \mathrm{C}\left(95^{\circ}\right.$ to to be given, more than one litre of intravenous infusion fluid may be required. Thoroughly agitate the prepared admixture untilcompletely clear. Complete solubilization of the drug as indicated by a completely clear solution, is ascertained by careful visual inspection. as indicated by a completely clear solution, is ascertained by careful visual inspection.

Dilution should be made just prior to administration and the solution should be used within 48 hours. Any unused portion should be discarded.

Administration. Using aseptic technique. slowly infuse the total daily dose by hour period.

Availability. Vira-A (Vidarabine for Infusion), a sterile suspension containing $200 \mathrm{mg} / \mathrm{ml}$ is supplied in $5 \mathrm{ml}$ Steri-Vials; packages of 10

Animal Toxicology

Acute Toxicity. The intraperitoneal LDso for Vira-A ranged from 3,890 to $4,500 \mathrm{mg} / \mathrm{kg}$ in mice, and from 2,239 to $2,512 \mathrm{mg} / \mathrm{kg}$ in rats, suggesting a low order of toxicity to a single parenteral dose. Hepatic megalocytosis was observed in rats after single, intraperitoneal injections at doses near and exceeding the LDso value. The hepatic megalocytosis appeared to regress over several months. Acute intravenous LDso values could not be obtained because of the limited solubility of Vira-A

Subacute Toxicity. Rats, dogs, and monkeys have been given daily intramuscular injections of Vira*A as a $20 \%$ suspension for 28 days. These animal species showed dose depression was also observed in monkeys. Except for localized, injection-site injury and weight gain inhibition or loss, rats tolerated daily doses up to $150 \mathrm{mg} / \mathrm{kg}$, and dogs tolerated daily doses up to $50 \mathrm{mg} / \mathrm{kg}$. Megalocylosis was not seen in the rats dosed by the intramuscular route for 28 days.

intramuscular route foll drug-treated males and the high and mid-dose females had moderate to marked increase in spleen weight at the end of the treatment period.

marked increase in spleen weight at the end of the treatment period. Rhesus monkeys were particularly sensitive to Vira-A. Daily intramuscular doses of 15
$\mathrm{mg} / \mathrm{kg}$ were tolerable, but doses of $25 \mathrm{mg} / \mathrm{kg}$ or higher induced progressively severe clinical signs of CNS toxicity. Three monkeys given slow intravenous infusions of Vira-Ain Tumorigenicity. Chronic parenteral (IM) studies of vidarabine have been conducted in mice and rats.

In the mouse study, there was a statistically significant increase in liver tumor incidence in same study some vidarabine-treated male mice developed kidney neoplasia. No renal tumors were found in the vehicle-treated control mice or the vidarabine-treated female mice.

Ine rat study, intestinal, testicular, and thyroid neoplasia occurred with greater frequency among the vidarabine-treated animals than in the vehicle-treated controls. The increases in thyroid adenoma incidence in the high-dose $(50 \mathrm{mg} / \mathrm{kg})$ males and the lowose $(30 \mathrm{mg} / \mathrm{kg})$ females were statistically significant.

Hepatic megalocytosis, associated with vidarabine treatment, has been found in short a preneoplastic change.

a prengenicity. Resulls of in vito experim ind corporated into mammalian DNA and can induce mutation in mammalian cells (mouse
L5178Y cell line). Thus far in vivo studies have not been as conclusive, but there is some evidence (dominant lethal assay in mice) that vidarabine may be capable of producing mutagenic effects in male germ cells.

It has also been reported that vidarabine causes chromosome breaks and gaps when added to human leukocytes in vitro. While the significance of these effects in terms of mutagenicity is not fully understood, there is a well-known correlation between the ability of various agents to produce such effects and their ability to produce heritable genetic damage. 


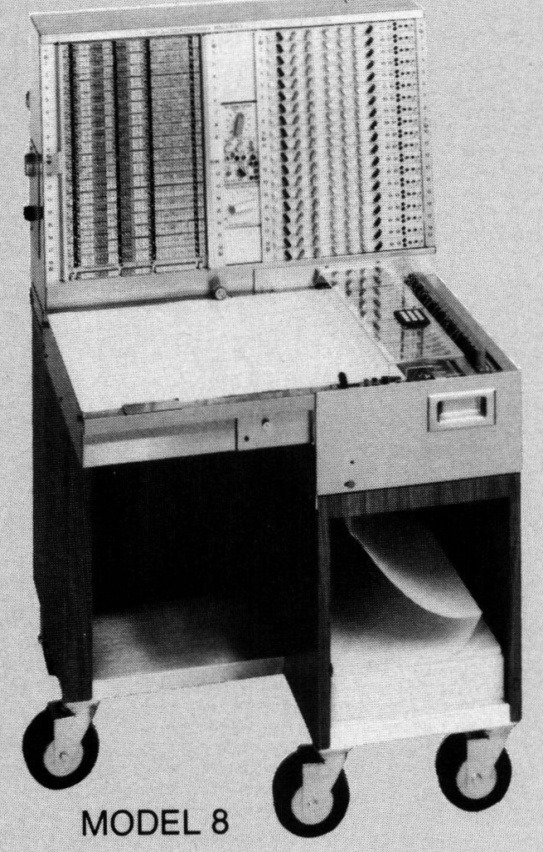

\section{POLYSOMNOGRAPHIC RECORDING FOR CLINIC OR RESEARCH}

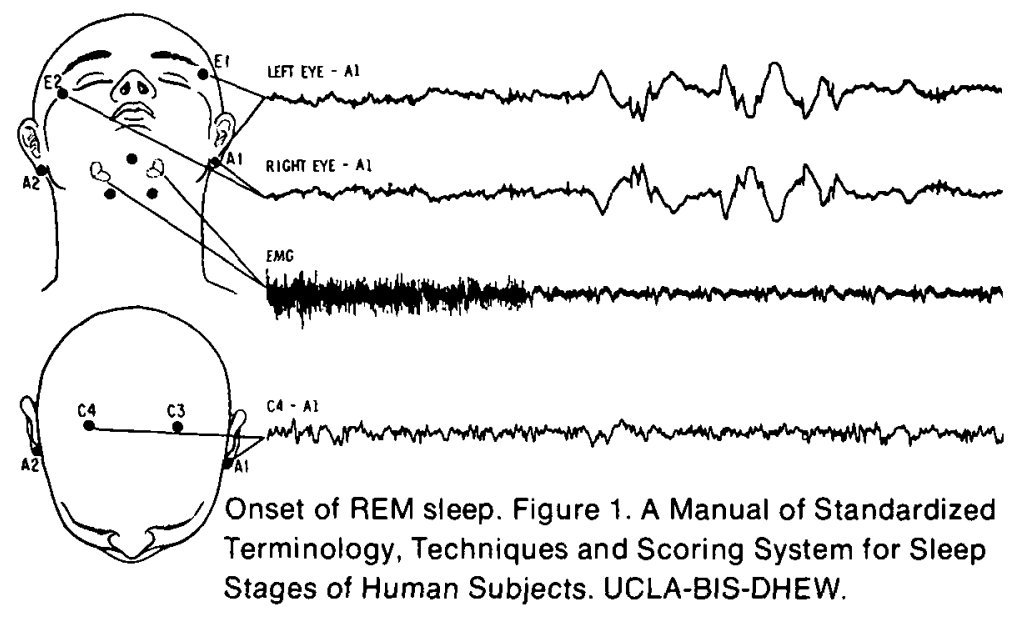

For multiple parameter recording of sleep-wake disorders in the clinical or the research setting, Grass Polygraphs and EEGs have the reliability and flexibility required.

For research applications, the Model 78 Polygraph with a wide selection of interchangeable signal conditioning preamplifiers allows recording several channels of EEG, EOG, EMG, ENG, temperature, respiration, EKG, blood gases, etc., with convenience and ease. A wide range of transducers, recording accessories, plus multiple chart speeds, including the widely used $10 \mathrm{~mm} / \mathrm{sec}$, provide a complete sleep-wake recording system.

For dual purpose applications where the primary interest is in clinical EEG and the secondary interest involves multiple parameter sleep studies, the Model 8 EEG is the instrument of choice.

For dependable long-term studies - rely on Grass, recording bioelectric activity since 1935 .

Write for further information on a system to meet your polysomnographic recording needs.

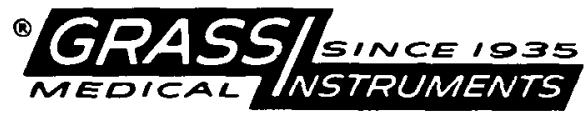

QUINCY, MASS. $02169 \cdot 617 / 773-0002$ 